\title{
SEASAT ALTIMETER OBSERVATIONS OF AN ANTARCTIC "LAKE"
}

\author{
by
}

\author{
W. Cudlip and N.F. McIntyre
}

(Mullard Space Science Laboratory, University College London, Holmbury St. Mary, Dorking, Surrey RH5 6NT, England)

\section{ABSTRACT}

The word "lake" in the context of Antarctica has been used to describe both surface features $(10-12 \mathrm{~km}$ in size) and areas of liquid water on the bedrock beneath the ice sheet (typically a few kilometres in size and at a depth of over $3000 \mathrm{~m}$ ). There has been however only limited evidence for a relationship between the two phenomena.

This paper reports an analysis of Seasat altimeter observations of an extremely flat area on the surface of the East Antarctic ice sheet, approximately $30 \mathrm{~km}$ in extent, centred at $68.6^{\circ} \mathrm{S} 136.0^{\circ} \mathrm{E}$ and close to the edge of the sub-glacial Astrolabe Basin. It has a regional slope of between zero and $0.01^{\circ}$, and non-random variations in height along track of about $\pm 1 \mathrm{~m}$ on the scale of a few kilometres. The average radar backscatter coefficient is $5 \pm 2 \mathrm{~dB}$ in the region of the Astrolabe Basin, compared to a more usual value of about $10 \mathrm{~dB}$ for other areas of the ice sheet. A computer enhanced Landsat image of the region clearly shows the rougher steeper terrain to the North, with the surface in and around the flat area appearing totally smooth and featureless.

NSF/SPRI/TUD radio echo-sounding data from the region, although limited in extent, shows a relatively strong signal (indicative of ice at the pressure melting point) over a large region. The signal under the flat area, however, is particularly strong and smooth, confirming the association between the surface feature and a bedrock lake $3800 \mathrm{~m}$ below.

\section{INTRODUCTION}

Robinson (1964), senior navigator with the Soviet Antarctic Expedition of 1959, reported ".........oval depressions with gentle 'shores' which are visible from an airplane over the plateau. The depth of the depressions usually does not exceed $20-30 \mathrm{~m}$. These unusual depressions are sometimes called 'lakes' by pilots". At that time, however, there was no reason to associate these visual lakes with liquid water. Some years later, as the techniques of radio echo-sounding were developed, anomalously strong echoes at a depth of $4200 \mathrm{~m}$ near Sovetskaya (Robin and others 1970) were reported and a substantial area of water deep under the Antarctic ice was suggested as an explanation. Subsequent radio-echo observations by the NSF/SPRI/TUD radio echo-sounding programme have detected 57 examples of strong specular returns from smooth flat areas in the bedrock (Oswald and Robin 1973; Robin and others 1977; McIntyre unpublished). These authors conclude, in combination with other studies, that water pockets or lakes do exist under certain parts of the ice sheet. Most of the examples suggest lake size of the order of a few kilometres; however, there is evidence for a much larger lake near Vostok about $180 \times 45 \mathrm{~km}$ in size (Robin and others 1977). A flight over this lake did in fact give visual confirmation of a correlation between surface and bedrock features, with the "shores" showing as areas of whiter snow which corresponded well in some cases with the edges of the radio echo lake. The visibility of the surface lake was attributed to the difference in appearance between a uniform flat surface (the lake) and a gently sloping one (the shore). This could be due either to changes in albedo, caused by differences in relative sun angle, or directly to changes in texture resulting from different snow accumulation. This is the only link so far that suggests that the earlier reported surface "lakes" are in fact related to sub-glacial lakes.

Satellite altimeters, because of their ability to provide data for accurate maps of surface elevation, can be used to help quantify the ice-sheet surface characteristics of bedrock lakes. Towards this end, this paper reports the detection, using Seasat altimeter data, of a particularly flat area in East Antarctica, about $30 \mathrm{~km}$ in extent, which can be linked with such a sub-glacial lake.

\section{DATA AND ANALYSIS}

Although designed for use over the open ocean, the altimeter on board the Seasat satellite (operational between 28 June and 10 October 1978) provided useful data over non-ocean surfaces. However, the analysis and interpretation of such data is usually more difficult due to the geometric and dielectric variability of the terrain and to the inability of the range-tracker to stay securely locked onto a return echo that can change rapidly in both shape and delay time. This latter problem can be overcome to some extent by recalculating the range estimate from the return echoes, a process called retracking (Martin and others 1983).

The ability to derive from Seasat Altimeter data detailed topographic maps over ice sheets has already been demonstrated (Brooks and Norcross 1983; Zwally and others 1983); over the smoother and flatter areas a potential precision of $0.25 \mathrm{~m}$ (for $10 \mathrm{~Hz}$ data) has been quoted, degrading to $1.6 \mathrm{~m}$ over rougher, sloping surfaces. (Zwally and others 1983). This precision of the Seasat elevation data can result in much detail remaining hidden in a contour map with, say, a $25 \mathrm{~m}$ contour interval.

Fig.1, taken from Brooks (1983), shows a $25 \mathrm{~m}$ contour map of a part of Wilkes Land in East Antarctica. Marked on this map are two sections of Seasat altimeter tracks A and $B$ which intersect over a local ice divide separating ice flowing towards Frost and Mertz Glaciers. The retracked elevation profiles along these tracks, derived from Seasat Sensor Data Record (SDR) tapes of waveform data, are shown in Fig.2. The echoes received over this section of the ice sheet were sufficiently similar in shape to those received over the ocean to justify retracking the waveforms using a threshold of $50 \%$ of peak return power (Partington and others 1987, this conference). This was sufficient to provide measurements of the mean surface elevation to a precision of $\pm 1 \mathrm{~m}$ within the pulse-limited altimeter footprint of about $1.75 \mathrm{~km}$. Slight distortions of the waveforms observed in some locations did not warrant the use of a more sophisticated retracker.

Despite the frequent loss of lock of the altimeter, it can be seen from Fig.2, track A, that there is a marked transition from an upward slope to a very flat region near the point of intersection. Unfortunately, the beginning of the flat area is lost due to the loss of lock, and the altimeter again loses lock soon after leaving the flat area. 


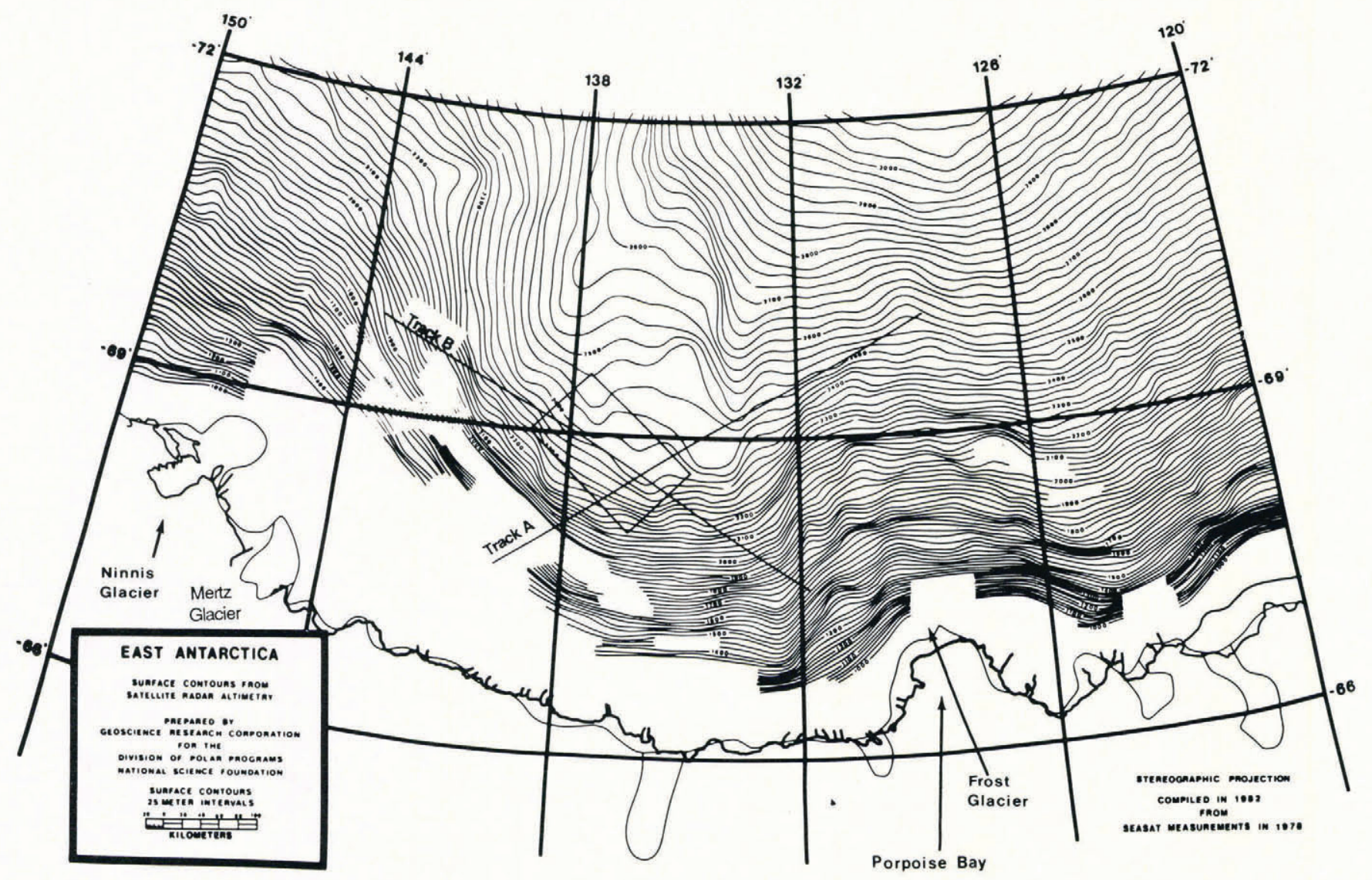

Fig.1. Contour map of part of Wilkes Land, East Antarctica compiled from over 27000 measurements by the Seasat radar altimeter and contoured at a $25 \mathrm{~m}$ interval (Brooks 1983). Also shown are the Seasat ground tracks used in Fig.2 (A and B) and the area recontoured in detail in Fig.3.
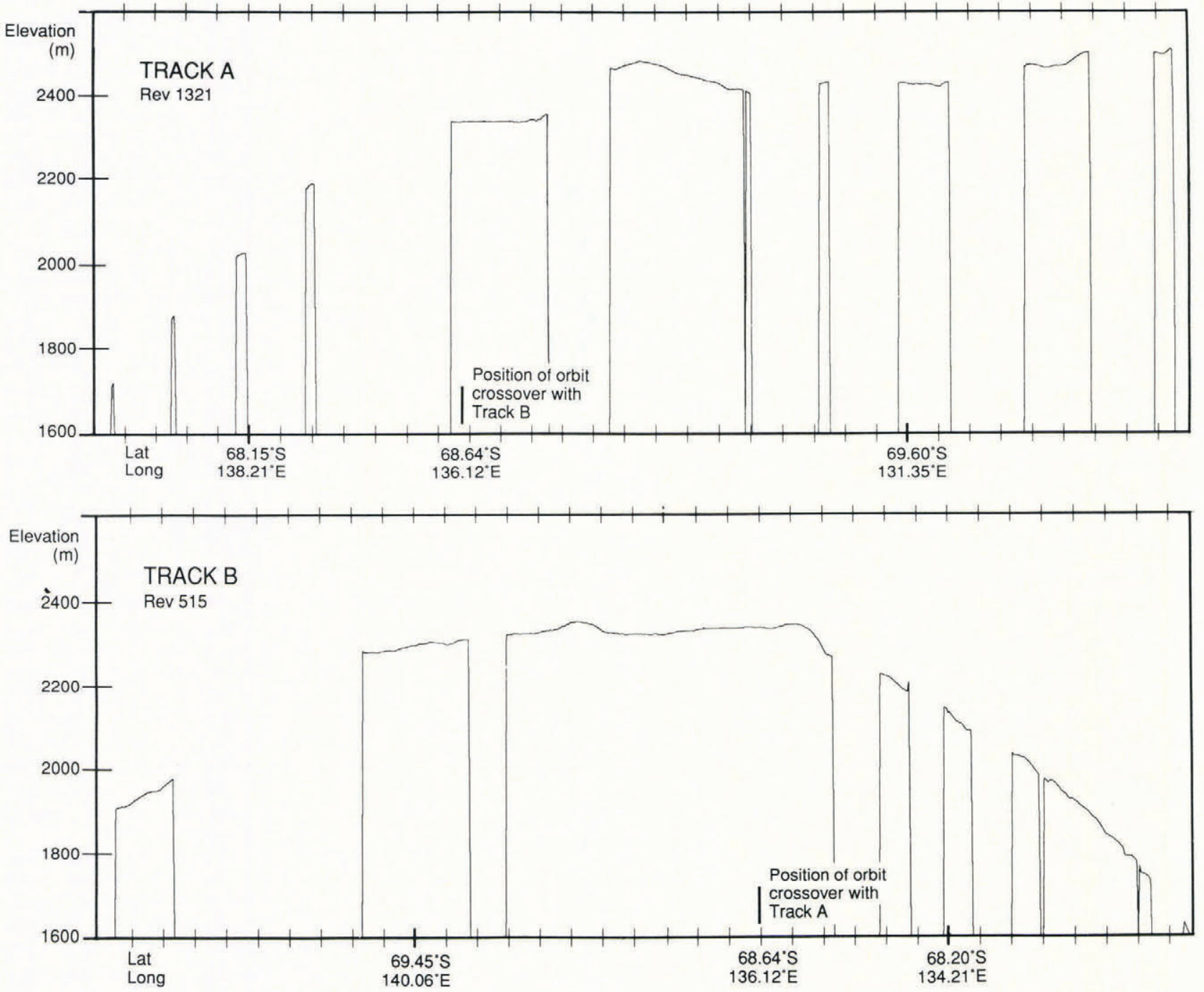

Fig.2. Two tracks of ice sheet surface elevations derived from Seasat altimetry data showing their

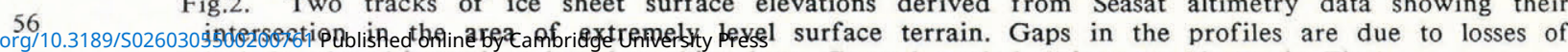
lock by the altimeter's onboard tracking loop. Ground track locations are shown in Fig.1. 
Track B also shows the surface to be flat where it intersects with track $\mathrm{A}$, demonstrating that the flat area extends in two directions and is not merely the result of a track fortuitously aligned with a surface contour.

A linear least-squares fit to the elevation data over the flattest parts of tracks $A$ and $B$ gives the following gradients and root mean square deviations:

$$
\text { length gradient }
$$

rms deviation

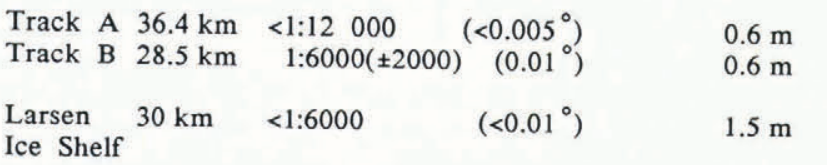

For comparison, the table also shows values for a length of track from the central part of the Larsen Ice Shelf. The gradient and deviations are similar. The data over these two areas could be retracked with a more sophisticated retracker (e.g. a least-squares, five-parameter, ocean-like fit) (Martin and others 1983) in order to reduce random retracking errors, but this is unlikely to reduce the rms deviations given above, as close examination of the elevation profiles does show some non-random variation in height of $\pm 1 \mathrm{~m}$ with a scale length of a few kilometres. Other comparable lengths of track can be found on the ice-sheet with similar gradients, but these have larger standard deviations (of $\approx 1.5 \mathrm{~m}$ or more) and appear to be chance alignments with contours.

Fig.3a shows a more detailed contour map of the region around the intersection of the tracks $A$ and $B$. This has been compiled from 9 tracks of retracked Seasat altimetry data and contoured by hand to an interval of 5 metres. The surface-elevation values are with respect to the Seasat's orbital reference ellipsoid $(a=6378.137 \mathrm{~km}$, $\mathrm{f}=1 / 298.257)$ and use the orbital parameters from the SDR tapes.

As we are concerned only with relative changes in surface elevation, no atmospheric or other corrections have been applied to the data. Analysis of the 8 orbit crossovers in the area of Fig. 3 revealed a mean difference of $0.6 \mathrm{~m}$ and a standard deviation of $\pm 1.6 \mathrm{~m}$. As this was of similar magnitude to the uncertainty in the individual elevation estimates, no correction for orbit errors was deemed necessary. Similarly, no correction for slope-induced error was carried out since for slopes of $0.1^{\circ}$ this amounts to only $1 \mathrm{~m}$; the flat area would thus be unaffected by this correction although other parts of the map would be subject to error. The portions of the altimeter tracks with valid data used in the construction of the contour map are shown in Fig.3b. Many more Seasat orbits crossed the area of Fig. 3 but these were repeat or near repeat tracks. The density of tracks is mostly limited by the maximum repeat orbit of 17 days used by the Seasat satellite, together with the relatively short lifetime of the mission ( 3 months).

The flat area at the centre of Fig. 3 is bounded to the south and west by higher ground, and by lower ground to the east and north. There does not appear to be a common surface feature with an elevation change of more than a metre which could be identified as a "lake shore" surrounding the flat area; however, the relatively rapid change in gradient around the flat area might make it distinguishable to an airborne observer. Similarly, although changes of a factor 2 in return power in this region of the Astrolabe Basin can be seen in the return waveforms, there is no marked difference between the flat section and the surrounding area. The normal-incidence backscatter coefficient (Moore and Williams 1957) over the flat area is $5 \pm 2 \mathrm{~dB}$, which is relatively low when compared with the more usual value of 10 or $11 \mathrm{~dB}$ seen over other areas of the ice sheet. An analysis of the backscatter coefficient over a much larger area of the ice sheet will have to be carried out before this lower value can be explained.

\section{COMPARISON WITH LANDSAT}

One of the few Landsat images of the area (path 90 , row 109, taken on 29 January 1973) was purchased in order
A $137^{\circ} \mathrm{E}$

$136^{\circ} \mathrm{E}$

$69^{\circ} \mathrm{S} 135^{\circ} \mathrm{E}$
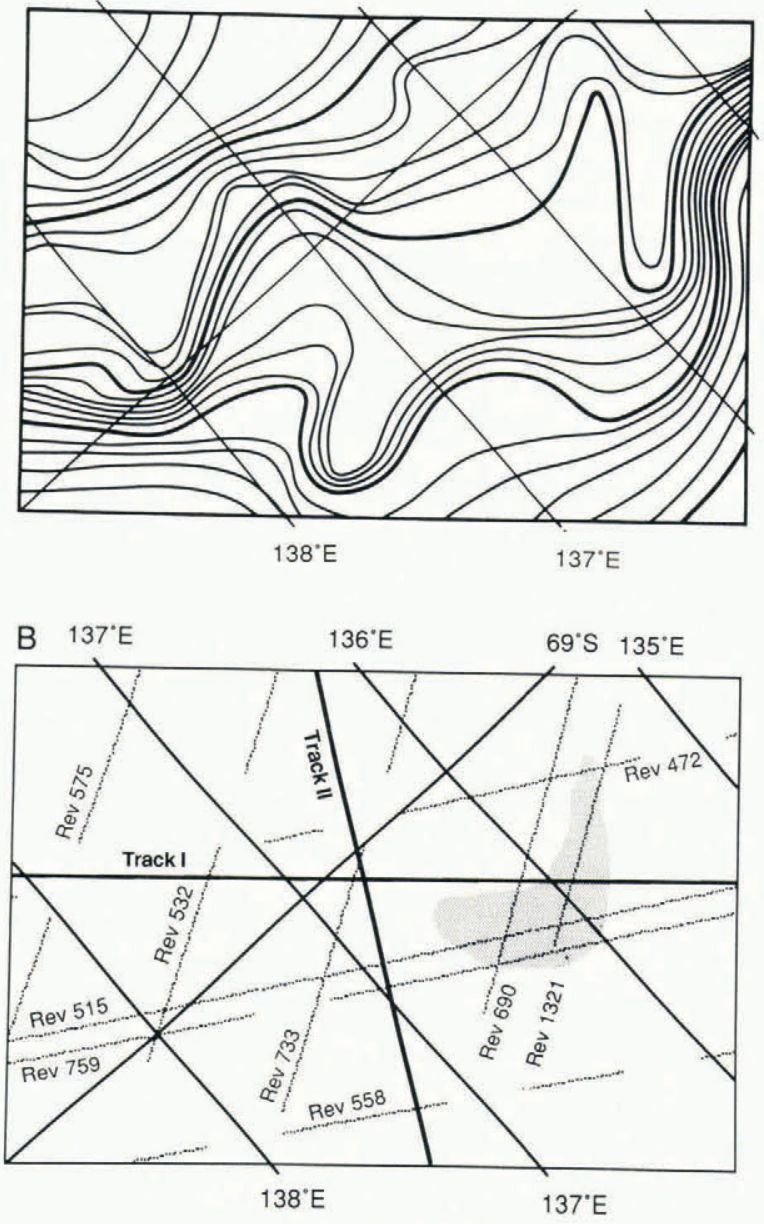

Fig.3. A: Contour map of ice sheet surface elevations in the boxed area of Fig.1. Contour interval is $5 \mathrm{~m}$ with every sixth contour drawn in bold. From the bottom, the bold contours are 2312, 2342 and $2372 \mathrm{~m}$ above Seasat's orbital reference ellipsoid. The estimated relative error on these contours is $\pm 2 \mathrm{~m}$.

B: Location of the 9 tracks of Seasat altimetry data (dotted lines) used to compile the contour map in A Two NSF/SPRI/TUD radio echo flight lines (I and II) are shown as bold continuous lines. The very flat terrain identified from the altimetry is shown as a stippled zone.

to compare the visible and radar observations. Fortunately, although half the area of the image was obscured by cloud, the lower half of the area of Fig. 3 was cloud-free. Bands 4 and 5 were saturated, as expected for many Landsat images over the ice sheet (Dowdeswell and McIntyre 1986). In bands 6 and 7, even after digitally processing the image with an extreme contrast stretch, no surface features were discernible on the flatter central area of Fig.3. However, the steeper area to the lower end of Fig.3a was clearly discernible as an apparently much rougher, pock-marked surface. There were no discernible surface features which could be attributed to the presence of a surface "lake" or "lake shore".

\section{COMPARISON WITH RADIO ECHO-SOUNDING}

Fig. 4 shows the ice-surface and bedrock profiles taken from two radio echo-sounding flights obtained during the NSF/SPRI/TUD campaign of 1974-75. The data are plotted for the lengths of the flight lines which intersect the area of Fig.3a, and the locations of the flight lines are shown in Fig.3b. These two flights provide the only radio echo-sounding data directly over or close to the area of the flat surface. As can be seen in Fig.3b, neither of the lines are exactly coincident with Seasat ground tracks and so care 
Radio echo sounding bedrock and surface elevation profiles
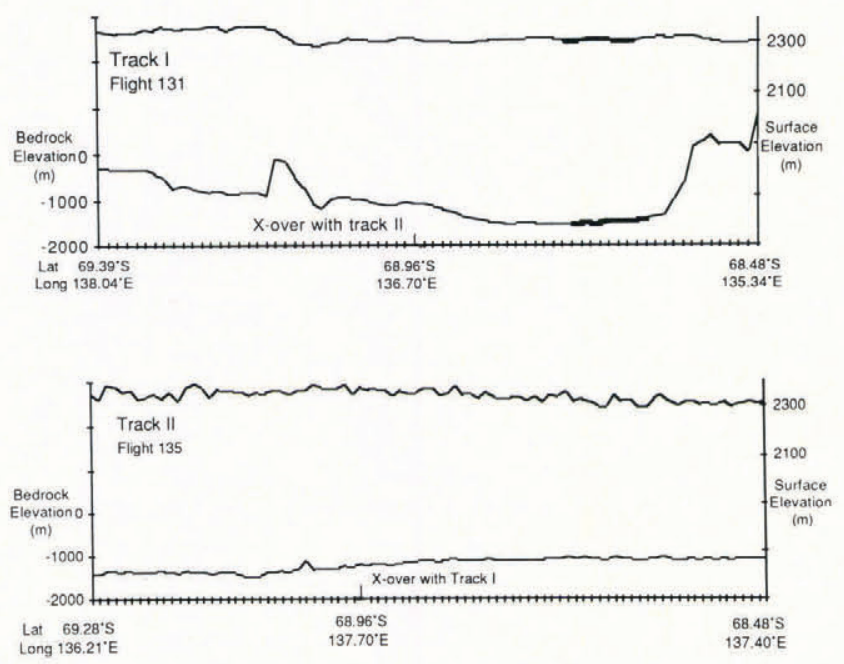

Fig.4. Surface and bedrock profiles from two NSF/SPRI/TUD radio echo-sounding flights (I and II) with ground tracks shown in Fig.3b. Note the different vertical scales for bedrock and surface profiles. The point of intersection of each is marked. The section of exceptionally bright and uniform return in track $I$, identified as a sub-glacial lake, is shown in bold on the bedrock profile, and the intersection of track I with the stippled lake area of Fig.3b is shown in bold on the surface profile.

must be taken in any comparison between these and Seasat data.

Track I is from a flight line along the length of the Astrolabe Basin, which has been described as a valley similar to the Great Rift Valley in East Africa. The surface and bedrock profiles along the whole flight line can be found in Steed and Drewry (1982). Almost the whole of Fig. 3 appears to lie over a relatively flat bedrock shelf about $70 \times 70 \mathrm{~km}$ at the northern end of the basin. The ice thickness in this area is between 3800 and $4000 \mathrm{~m}$, while over the deepest part of the basin it increases to $4670 \mathrm{~m}$.

A study of the original photographic record of these flights shows the echo returns to be relatively strong over the whole area but with a short section of track II being particularly strong and smooth. This short section, $16.5 \mathrm{~km}$ in length (shown highlighted in Fig.4b), shows good agreement with the flat surface area mapped with the Seasat altimeter (Fig.3). The strong return over the whole area suggests the presence of ice at the pressure melting point (Oswald 1975) over most of the shelf area, and the particularly strong section suggests a body of water a metre or more in depth i.e. a subglacial lake directly beneath the area of particular surface flatness. The presence of a lake at this location was suggested by McIntyre (unpublished) on the basis of the radio echo-sounding data alone.

A linear least-squares fit to the bedrock elevation over the $16.5 \mathrm{~km}$ of strongest return in track II gives a gradient of $1: 160 \pm 20$, which compares with values of $1: 70 \pm 10$ and 1:50 \pm 10 determined for some other sub-glacial lakes (Oswald 1975). The mean surface elevation derived from radio echo-sounding data over the same length of track is $2310 \mathrm{~m}$ with a standard deviation of $\pm 4 \mathrm{~m}$. This compares with a geoid-corrected value derived from the Seasat data of $2295 \pm 2 \mathrm{~m}$. (The geoid correction using the GEM 10b model is $45.1 \mathrm{~m}$ at this location, and the local Geoid gradient is $\left.0.001^{\circ}\right)$. This residual difference of about $15 \mathrm{~m}$ is well within the absolute calibration error of the radio echo-sounding data which has been estimated to be $\pm 50 \mathrm{~m}$ (Steed and Drewry 1982).

\section{DISCUSSION AND SUMMARY}

The removal of basal friction over an area of tens of kilometres must be expected to produce some effect on ice flow and hence the upper surface of an ice sheet (Whillans and Johnsen 1983), even though local ice thickness may be $3000 \mathrm{~m}$ or more. This effect was predicted by Robin and others (1977) for the Vostok Lake, but sufficiently accurate data were not available to provide more than visual confirmation. With Seasat altimetry data we have shown these predictions to be correct, even though applying to a much smaller area of basal water.

Most of the sub-glacial lakes found to date are in areas of low surface slopes and low ice velocity; there are high concentrations near Dome Circe and Ridge B. The location of the lake observed here is, however, unusual in that it is much closer to the Wilkes Land coast $(250-300 \mathrm{~km})$ than most previous observations of pressure melting or sub-glacial lakes (about $700 \mathrm{~km}$ at Dome Circe). The surface conditions for its occurrence are provided by the local ice divide shown in Fig.1, the location of which was not clearly demonstrated until production of the surface-elevation map with Seasat data. This would suggest first the importance of generating accurate topographic maps using satellite altimetry data as an aid to studies of ice-sheet dynamics; and, secondly, that prerequisities for the formation of lakes (such as high geothermal heat flux) (Oswald 1975) may exist over wider areas than previously thought.

The discovery of a large flat area on the ice-sheet which is even flatter than the major portion of the central ice sheet is also important from the point of view of future satellite missions. It has been suggested that the level topography of the central areas of ice sheets be used as reference surfaces for the calibration of the satellite orbits (Gorman and Drewry 1984), since they have advantages over tropical sites in terms of atmospheric corrections, smooth terrain and tidal variations. It is possible that the surface of ice sheets in the region of subglacial lakes will offer exceptionally smooth sites for altimeter calibration. The large subglacial lake near Vostok and other smaller ones near Dome Circe and Ridge $B$ will be within the orbital limit of the European Space Agency's ERS-1 satellite $\left(82^{\circ} \mathrm{N}\right.$ and S) and could be considered for this purpose.

\section{ACKNOWLEDGEMENTS}

We are most grateful to Dr D J Drewry of the Scott Polar Research Institute for providing access to the radio echo-sounding data. WC and NFM acknowledge the receipt of NERC and SERC PDRAs respectively.

\section{REFERENCES}

Brooks R L 1983 Scientists use satellite data to map ice-sheet contours. Antarctic Journal of the United States 18(2): $17-18$

Brooks R L, Norcross A N 1983 East Antarctic ice sheet surface contours from satellite radar altimetry - $a$ demonstration. Salisbury, MD, Geoscience Research Corporation

Dowdeswell J A, McIntyre N F 1986 The saturation of LANDSAT MSS detectors over large ice masses. International Journal of Remote Sensing 7(1): 151-164

Gorman M R, Drewry D J 1984 Ice sheets as invariant surfaces for radar altimeter calibration and orbit determination. In Guyenne $\mathrm{T} \mathrm{D}$, Hunt J J (eds) ERS-1 Radar Altimeter Data Products. Proceedings of an ESA workshop held at Frascati, Italy on 8-11 May, 1984. Paris, European Space Agency: 173-176 (SP221)

McIntyre N F Unpublished The topography and flow of the Antarctic ice sheet. (PhD thesis, University of Cambridge, 1983)

Martin T V, Zwally H J, Brenner A C, Bindschadler R A 1983 Analysis and retracking of continental ice sheet radar altimeter waveforms. Journal of Geophysical Research 88(C3): 1608-1616

Moore R K, Williams C S 1957 Radar terrain return at near vertical incidence. Proceedings of the Institute of Radio Engineers 45(2): 228-238

Oswald G K A 1975 Investigation of sub-ice bedrock characteristics by radio-echo sounding. Journal of Glaciology 15(73): 75-87

Oswald G K A, Robin G de Q 1973 Lakes beneath the Antarctic ice sheet. Nature 245(5423): 251-254 
Partington K C, Cudlip W, McIntyre N F, King-Hele S 1987 Mapping of Amery Ice Shelf, Antarctica, surface features by satellite altimetry. Annals of Glaciology 9: 183-188

Robin G de Q, Swithinbank C W M, Smith B M E 1970 Radio echo exploration of the Antarctic ice sheet. International Association of Scientific Hydrology Publication 86 (ISAGE): 97-115

Robin G de Q, Drewry D J, Meldrum D T 1977 International studies of ice sheet and bedrock. Philosophical Transactions of the Royal Society of London Ser B 279(963): 185-196

Robinson R V 1964 Experiment in visual orientation during flights in the Antarctic. Soviet Antarctic Expedition. Information Bulletin 2: 233-234

Steed R H N, Drewry D J 1982 Radio-echo sounding investigations of Wilkes Land, Antarctica. In Craddock C (ed) Antarctic geoscience. Symposium on Antarctic Geology and Geophysics, Madison, Wisconsin, U.S.A., August 22-27, 1977. Madison, IVI, University of Wisconsin Press: 969-975

Whillans I M, Johnsen S J 1983 Longitudinal variations in glacial flow: theory and test using data from the Byrd Station strain network, Antarctica. Journal of Glaciology 29 (101): 78-97

Zwally H J, Bindschadler R A, Brenner A C, Martin T V, Thomas R H 1983 Surface elevation contours of Greenland and Antarctic ice sheets. Journal of Geophysical Research 88(C3): 1589-1596 